Ryan, John Haughney and Wisia Wedzicha (who provided very helpful strategic advice).

As ever, we are extremely grateful to our superb team of assistant, statistical, section and associate editors, as well as the PCRS-UK and IPCRG representatives and everyone on the PCRJ International Editorial Board, for their support and guidance. We must also thank everyone who has contributed their time and expertise to review manuscripts for the PCRJ in 2013; this work, undertaken despite very busy schedules by experts in their field, is fundamental to our success in publishing high quality peerreviewed articles, and we are enormously grateful. The list of PCRJ 2013 reviewers is available online at www.thepcrj.org as an appendix to this editorial.
Finally, we would like to record our debt of gratitude to the team in the $P C R J$ editorial office, who have provided us with such stalwart support over many years. Led by Tricia Bryant and ably supported by Gail Ryan, Helen McDonnell, Liz Stockman, and Lynn Danzig, they have been the backbone of the journal. The success of the PCRJ and its continued development is in no small part a tribute to their dedication and hard work.

Conflicts of interest The authors declare that they have no conflicts of interest in relation to this article.

Online 28th February 2014

(C) 2014 Primary Care Respiratory Society UK. All rights reserved http://dx.doi.org/10.4104/pcrj.2014.00022 Prim Care Respir J 2014; 23(1): 1-2

\title{
Vitamin D and the HLA locus help to explain the relationship between autoimmune and allergic diseases
}

\section{See linked article by Maas et al. on pg 14}

\section{*Scott T Weiss ${ }^{1}$}

1 Professor of Medicine, Harvard Medical School; Associate Director, Channing Division of Network Medicine, Brigham and Women's Hospital, Boston MA, USA

*Correspondence: Professor Scott T Weiss, Professor of Medicine, Harvard Medical School, Department of Medicine, Brigham and Women's Hospital, Boston MA 02115, USA Tel: +617525 2278 Fax: +617525 4488

E-mail: scott.weiss@channing.harvard.edu

Autoimmunity has been defined as a T-helper cell type $1(\mathrm{Th} / 1)$ immune phenomenon, which creates an inflammatory response in the body against normal body substances (tissues/proteins). Allergy on the other hand is a T-helper cell type $2(\mathrm{Th} / 2)$ immune response to foreign antigen that also leads to inflammation. Because these two classes of immune disorders involve different clusters of differentiation 4 (CD4+) T-helper cell subsets, hitherto they have been considered immunologically separate and distinct - i.e. not caused by the same underlying genetic and environmental factors. However, in this issue of the PCRJ, Maas and colleagues have studied the co-occurrence of these immune diseases in families in the general population of the Netherlands, and have found that a diagnosed autoimmune disease in the parents suggested a roughly 2-fold increased risk of allergic disease in the eldest child. ${ }^{1}$ Their data suggest that there may be more of a common aetiology for these two types of immune disorders than previously thought. 2,3

Critical to the interpretation of the paper by Maas et al. is the issue of disease classification. The investigators used the International Classification of Primary Care (ICPC) diagnoses to define autoimmune disease in the parents. This system identifies the seven most common autoimmune diseases: psoriasis, rheumatoid arthritis/ankylosing spondylitis, ulcerative colitis/Crohn's disease, diabetes mellitus type 1, and multiple sclerosis. There are many more autoimmune diseases that were excluded from consideration because they are rare and hence not included in the ICPC. Including these rarer disorders might have made the results of the study even stronger. The allergic diseases classified included allergic asthma, hay fever, atopic dermatitis, and atopic conjunctivitis. This disease classification was relatively complete and thus misclassification bias is unlikely to have occurred for this outcome. Another methodological concern is that non-paternity was assessed and judged to be at an acceptable level; again, more stringent criteria for non-paternity would only have strengthened the results.

As noted by the authors, ${ }^{1}$ epidemiological data suggesting familial aggregation of these types of immune disorders in families is conflicting, and for some studies, statistical power has been limited by the low prevalence of the autoimmune diseases. Again, as noted by the authors, small sample size was an issue in some of the prior studies, as well as incomplete ascertainment of autoimmune disease. ${ }^{4.5}$ In contrast to the autoimmune diseases, the prevalence of allergy is high, and thus familial aggregation can occur simply by high disease prevalence alone.

The central question is whether this disease co-occurrence is just due to the nonspecific "environmental and epigenetic and genetic effects" alluded to by Maas and colleagues, ${ }^{1}$ or is there a hypothesis that might explain the underlying co-occurrence of autoimmune and allergic diseases in families?

I think there is a hypothesis as to what has caused a rise in prevalence of both Th1- and Th2-mediated immune diseases. First, the rise in both Th2 and Th1 immune diseases suggests that the immunological defect is at the next level up from the CD4 +, Th1, and Th2 cell, namely at the level of the T-regulatory cell (T-reg); these cells control both Th2 and Th1 inflammatory responses. These T-reg cells are in turn under the control of vitamin D, corticosteroids, and the cellular cytokines Transforming Growth factor Beta one (TGFB1) and 
interleukin 10 (IL10). Higher levels of vitamin D lead to up-regulation of IL10 and TGFB1, the subsequent up-regulation of effector Tregulatory cell activity, and the down-regulation of inflammation (both Th1 or Th2). ${ }^{6}$ In addition, higher levels of vitamin D lead to decreased dendritic cell signaling to the T-regulatory cells, which means a decreased antigenic input to these controller cells. ${ }^{6}$ Finally, vitamin $D$ levels are important epigenetic activators that establish signalling between mother and fetus and induce downstream gene expression in over 5000 genes when comparing the sufficient and the deficient states of the mother. ${ }^{7}$

There are several features that are attractive about this theory. First, it provides a plausible set of environmental factors - e.g. sun exposure, cod liver oil intake, and subsequent vitamin D levels - to explain the epidemiology of a rise in both Th1 and Th2 disease over the past 50 years, a time when vitamin $\mathrm{D}$ levels in the population have been decreasing. The causes of the epidemic of vitamin $D$ deficiency and its role in fetal development and disease have been well documented. ${ }^{6.8-12}$

However, whilst I believe that vitamin $D$ is responsible for much of the fetal origins of disease, vitamin $D$ deficiency alone cannot account for the wide variation in clinical disease phenotypes seen for both autoimmunity and allergy. As noted by Maas et al.,' there must also be a genetic component. I believe that the primary common genetic component is the HLA locus located on chromosome 6 . For both the allergic and the autoimmune diseases there are specific HLA genes that are associated with disease occurrence. Indeed, it is the combination of specific HLA genes and low vitamin D that results in each of the specific autoimmune and allergic diseases. Whether it is HLAB27 for ankylosing spondylitis or HLADRB1 for allergic asthma, the HLA alleles confer disease phenotype specificity in the setting of low vitamin D. This concept of a vitamin D-HLA interaction is not novel and is well established in the published literature; a Pub Med search identifies 239 articles on the relationship between vitamin D and HLA, including articles on all seven of the Th1 autoimmune diseases of the Maas study, and asthma. Are there other genes involved besides HLA? Almost certainly, there are. Further genomic studies in the relevant tissues will yield the networks of additional genes involved. However, it is specifically HLA interacting with vitamin D that gives these disorders a common pathophysiology.

Given this hypothesis there is one essential question: what can be done to prove that low vitamin D and HLA are the primary environmental and genomic drivers for the co-occurrence of these disorders? We need to do large randomised controlled trials of vitamin D supplementation to pregnant women at high risk of allergy or autoimmune disease where genomics are measured and the cooccurrence of allergies and autoimmune disease are also measured. The limiting factor will be the incidence of the autoimmune diseases. However, type-one diabetes is relatively common, and if coupled with multiple other autoimmune disease outcomes with sufficiently long follow-up, such a trial is feasible. Obviously, measurement of HLA in both parents and offspring in such a trial will be critical as well. While HLA genotype can't be changed, vitamin D deficiency can be looked for and addressed. This then represents an important possibility for intervention and prevention of all of these disorders.

Conflicts of interest The author is supported by NIH grants including a grant to study the effect of vitamin $D$ supplementation in pregnant women and prevention of asthma in their offspring: U01 HL091528.

Commissioned article; not externally peer reviewed; accepted 13th January 2014; online 19th February 2014

(C) 2014 Primary Care Respiratory Society UK. All rights reserved http://dx.doi.org/10.4104/pcrj.2014.00009

Prim Care Respir J 2014; 23(1): 2-3

\section{References}

1. Maas T, Nieuwhof C, Passos VL, et al. Transgenerational occurrence of allergic disease and autoimmunity: general practice-based epidemiological research. Prim Care Respir J 2014;23(1):14-21. http://dx.doi.org/10.4104/pcrj.2013.00108

2. Simpson CR, Anderson WJ, Helms PJ, et al. Coincidence of immune-mediated diseases driven by Th1 and Th2 subsets suggests a common aetiology. A population-based study using computerized general practice data. Clin Exp Allergy. 2002;32(1):37-42. http://dx.doi.org/10.1046/j.0022-0477.2001.01250.x

3. Sheikh A, Smeeth L, Hubbard R. There is no evidence of an inverse relationship between TH2-mediated atopy and TH1-mediated autoimmune disorders: Lack of support for the hygiene hypothesis. J Allergy Clin Immunol 2003;111(1):131-5. http://dx.doi.org/10.1067/mai.2003.8

4. Rudwaleit $M$, Andermann $B$, Alten $R$, et al. Atopic disorders in ankylosing spondylitis and rheumatoid arthritis. Ann Rheum Dis 2002;61:968-74. http://dx.doi.org/10.1136/ard.61.11.968

5. EURODIAB. Decreased prevalence of atopic diseases in children with diabetes. TheEURODIAB Substudy 2 Study Group. J Pediatr 2000;137:470-4. http://dx.doi.org/10.1067/mpd.2000.109109

6. Litonjua AA, Weiss ST. Is vitamin D deficiency to blame for the asthma epidemic? J Allergy Clin Immunol 2007;120(5):1031-5.

http://dx.doi.org/10.1016/j.jaci.2007.08.028

7. Bossé $\mathrm{Y}$, Lemire M, Poon AH, et al. Asthma and genes encoding components of the vitamin D pathway. Respir Res 2009;10:98.

http://dx.doi.org/10.1186/1465-9921-10-98

8. Weiss ST, Litonjua AA. Maternal diet vs lack of exposure to sunlight as the cause of the epidemic of asthma, allergies and other autoimmune diseases. Thorax 2007;62(9):746-8. http://dx.doi.org/10.1136/thx.2007.079707

9. Weiss ST, Litonjua AA. Childhood asthma is a fat-soluble vitamin deficiency disease. Clin Exp Allergy 2008;38(3):385-7. http://dx.doi.org/10.1111/j.1365-2222.2007.02920.x

10. Weiss ST. Asthma in early life: is the hygiene hypothesis correct? J Pediatr (Rio J) 2008;84(6):475-6. http://dx.doi.org/10.2223/JPED.1857

11. Weiss ST, Litonjua AA. The in utero effects of maternal vitamin D deficiency: how it results in asthma and other chronic diseases. Am J Respir Crit Care Med 2011;183(10):1286-7. http://dx.doi.org/10.1164/rccm.201101-0160ED

12. Weiss ST. Bacterial components plus vitamin D: the ultimate solution to the asthma (autoimmune disease) epidemic? J Allergy Clin Immunol 2011;127(5):1128-30. http://dx.doi.org/10.1016/j.jaci.2011.02.025 